\title{
Co-movement between residential and commercial housing prices: Evidence from a new database
}

\author{
Juan Carlos Cuestasa,b,c
}

\section{Mercedes Monfort ${ }^{\mathrm{a}}$}

${ }^{a}$ Department of Economics and IEI, Jaume I University, Spain.

${ }^{b}$ Department of Economics and Finance, Tallinn University of Technology, Estonia.

${ }^{c}$ Research Unit, Eesti Pank, Estonia.

\begin{abstract}
The aim of this paper is to shed some light on the issue of the co-movement between residential real estate and commercial real estate using a newly developed database by the Bank if International Settlements. Our results point for the existence of a unique common nonlinear trend in the five countries analysed.
\end{abstract}

Key words: housing market, macropudential policies, nonlinearities.

JEL classification: E21, E51, R20.

\section{Acknowledgements}

Juan Carlos Cuestas acknowledges the financial support from the MINEIC-AEI-FEDER ECO2017-85503-R and ECO2017-83255-C3-3-P projects, both of them from 'Ministerio de Economía, Industria y Competitividad' (MINEIC), 'Agencia Estatal de Investigación' (AEI) Spain and 'Fondo Europeo de Desarrollo Regional' (FEDER).

Email: cuestas@uji.es 


\section{Introduction}

Housing markets have been in the centre of the academic research since the beginning of the 2000s due to their evolution, both before and after the Great Recession. A number of countries have suffered from price bubbles bursts in the real estate sector, with the consequences of banking sector fragility, increased unemployment and deep recessions. In some countries, capital inflows have played a role in this evolution (Cuestas 2017), and in some others undistributed profits from corporations may have fuelled housing markets (Cuestas and Kukk 2019).

In this paper, we aim to analyse whether prices for residential housing and for commercial purposes share a co-movement, using a newly published database by the Bank of International Settlements (BIS). It is important to consider the evolution of the commercial real estate prices as this can affect the financial stability of the economy, provided that a sudden drop in commercial real estate prices can increase the probability of default of non-financial corporations, it can affect the procyclicality of the financial sector and the international contagion of a bust may be stronger than in residential real estate, as stated by Hkavacek et al. (2014). There is a vast literature on the analysis of co-movement of housing prices in general at the national or international level (see amongst others, Gupta and Das, 2008 and Gupta et al. 2015). Bianchi et el. (2015) analyse the factors behind the 2007-2009 potential mispricing for residential and not residential in the US.

However, to the best of our knowledge, this is the first attempt to analyse co-movement between residential and commercial real estate prices for a group of countries. This analysis can be important for policy making and macroprudential measures. If both variables wonder apart, i.e. they do not share any common trend, that means that policies aimed at one sector's prices may not have the same effects over the other. However, if both variables share a co-movement, it is likely that policy measures have a similar effect on both sectors, as their fundamentals would be very similar. Whether or not there are reasons to assume that both sector's price evolution should commove (see Robac, 1982, and Rosen, 1979 for theoretical models and Gyorku, 2009 for an

application for the US), there is a need for further empirical research to shed some light on the issue. For that we apply the Bierens (2000) nonlinear co-trending technique for a group of 
countries chosen due to data availability from the BIS database. ${ }^{1}$ The reminder of the paper is organised as follows. The next section presents the data. Section 3 presents the cross correlations and summarises the methodology applied in this empirical paper along with the results and, finally, the last section concludes.

\section{Data}

We use quarterly residential price property prices obtained from the BIS ${ }^{2}$ and commercial real estate prices for the following countries, which have been selected due to data availability: Brazil (2001Q1-2016Q4, series Q:BR:0:A:0:2:5:0 and Q:BR:N:628), Denmark(1) (1992Q1-2016Q2 series Q:DK:0:A:0:1:5:0 and Q:DK:0:8:0:1:0:0), Denmark(2) (2002Q4-2016Q2, series Q:DK:0:A:0:1:5:0 and Q:DK:0:8:0:1:0:0), Hong Kong (1993M1-2017M3, average series M:HK:0:B:0:1:1:0 and M:HK:0:C:0:1:1:0, and M:HK:0:1:0:1:1:0), Iceland (2000Q1-2016Q4, M:IS:0:1:0:1:1:0 which have been converted into quarterly series by selecting the last observation of each quarter and Q:IS:3:A:0:0:1:0), Indonesia (2002Q1-2016Q4, series Q:ID:3:B:2:0:1:0 and Q:ID:4:1:2:0:0:0), Republic of Korea (2004M12-2017M2, series M:KR:0:M:0:3:1:1 and M:KR:1:L:0:3:1:1), Singapore (1998Q1-2016Q4, average series Q:SG:0:B:0:3:1:0 and Q:SG:0:C:0:3:1:0, and Q:SG:0:1:0:3:1:0) and the US (1970Q1-2016Q4, series Q:US:0:A:0:2:6:0 and Q:US). Note that in the case of Denmark we have used two series, Denmark(1) contains only flats for residential dwellings, whereas Denmark(2) contains all dwellings. The reason is that the flats series start in 1992, whereas the series containing all dwellings start ten years later. We want to analyse the co-movement for both shorter and longer series. In the cases where two of more prices were reported in the database for any of the two, residential or/and commercial, we have computed the average value. Note that these are the only countries where we could find long enough series for both commercial and residential real estate prices.

\footnotetext{
${ }^{1}$ See next section for details.

${ }^{2}$ http://www.bis.org/statistics/pp.htm?m=6\%7C288
} 


\section{Results}

In Table 1 we report the cross-correlations for different leads and lags between commercial prices and residential prices real estate. As it can be seen the cross-correlations show a high degree of association for the different lags and leads considered. This can be an indication of the mutual dependence between both variables in our target countries.

\section{Table 1: Cross correlations}

\begin{tabular}{|c|c|c|c|c|c|c|c|c|c|c|c|c|c|c|c|c|}
\hline & \multicolumn{2}{|c|}{ Brazil } & \multicolumn{2}{|c|}{ Denmark(1) } & \multicolumn{2}{|c|}{$\operatorname{Denmark}(2)$} & \multicolumn{2}{|c|}{ Hong Kong } & \multicolumn{2}{|c|}{ Indonesia } & \multicolumn{2}{|c|}{ Rep. Korea } & \multicolumn{2}{|c|}{ Singapore } & \multicolumn{2}{|c|}{ USA } \\
\hline $\mathrm{i}$ & lag & lead & lag & lead & lag & lead & lag & lead & lag & lead & lag & lead & lag & lead & lag & lead \\
\hline 0 & 0.99 & 0.99 & 0.91 & 0.91 & 0.71 & 0.71 & 0.98 & 0.98 & 0.97 & 0.97 & 0.99 & 0.99 & 0.87 & 0.87 & 0.95 & 0.95 \\
\hline 1 & 0.96 & 0.96 & 0.89 & 0.88 & 0.72 & 0.64 & 0.97 & 0.97 & 94 & 0.92 & 0.96 & 0.96 & 90 & 0.81 & 0.94 & 0.92 \\
\hline 2 & 0.94 & 0.92 & 0.00 & 0.86 & 72 & 0.54 & 0.95 & 0.96 & 0.90 & 0.87 & 0.92 & 0.92 & 0.91 & 0.74 & 0.92 & 0.89 \\
\hline 3 & 0.91 & 0.89 & 0.86 & 0.81 & 66 & 0.38 & 0.94 & 0.96 & 0.85 & 0.81 & 0.88 & 0.88 & 0.89 & 0.68 & 0.91 & 0.87 \\
\hline 4 & 0.87 & 0.85 & 0.84 & 0.77 & 0.61 & 0.26 & 0.92 & 0.95 & 0.80 & 0.75 & 0.84 & 0.84 & 0.86 & 0.63 & 0.90 & 0.84 \\
\hline 5 & 0.83 & 0.81 & 0.83 & 0 & 57 & 0.17 & 0.91 & 0.94 & 0.76 & 0.69 & 0.80 & 0.81 & 0.81 & 0.59 & 0.88 & 0.81 \\
\hline 6 & 0.79 & 0.77 & 0.81 & 0.72 & 0.52 & 0.06 & 0.89 & 0.93 & 70 & 0.62 & 0.76 & 0.77 & 77 & .55 & 0.86 & 0.79 \\
\hline 7 & 0.74 & 0.73 & 0.78 & 0.69 & 0.45 & -0.06 & 0.87 & 0.92 & 0.03 & 0.55 & 0.72 & 0.73 & 0.73 & 0.51 & 0.84 & 0.76 \\
\hline 8 & 0.69 & 0.68 & 0.76 & 0.67 & 0.37 & -0.12 & 0.86 & 0.91 & 0.00 & 0.49 & 0.69 & 0.70 & 0.70 & 0.48 & 0.83 & 0.74 \\
\hline 9 & 0.64 & 0.64 & 0.74 & 0.65 & 0.30 & -0.17 & 0.84 & 0.90 & 0.54 & 0.43 & 0.65 & 0.66 & 68 & .44 & 0.80 & 0.71 \\
\hline 10 & 0.59 & 0.59 & 0.71 & 0.62 & 0.22 & -0.24 & 0.82 & 0.89 & 0.49 & 0.37 & 0.62 & 0.63 & 0.67 & 0.40 & 0.78 & 0.69 \\
\hline
\end{tabular}

Note: The table shows the cross-correlations for different lags (-i) and leads (+i) for the pair commercial prices, residential prices $(-\mathrm{i}),(+\mathrm{i})$.

In order to formally assess the hypothesis of co-movement, we apply the Bierens (2000) approach to detect the existence of nonlinear common trends by means of nonparametric methods. Since this approach is nonparametric it is not required that both variables are I(1), unlike with cointegration techniques, as if they variables are I(0) the test becomes a deterministic co-trending analysis. Hence, the statistic developed tests the null hypothesis that there is a nonzero vector $\theta$ such that $\theta^{T} g(t)$ is a linear trend, where $g(t)$ is a nonlinear trend. The test is related to obtaining the solutions for the generalised eigenvalue problem

$$
\left|\widehat{M}_{1}-\lambda \widehat{M}_{2}\right|=0
$$

for the components of the vector $\lambda$, which will give us the number of co-trending vectors $r$, where 


$$
\begin{gathered}
\widehat{M}_{1}=\frac{\hat{F}(1 / n) \hat{F}(1 / n)^{T}+\cdots+\hat{F}(1) \hat{F}(1)^{T}}{n} \\
\widehat{M}_{2}=\frac{\widehat{F}^{\prime}(1 / n) \widehat{F}^{\prime}(1 / n)^{T}+\cdots+\widehat{F}^{\prime}(1) \hat{F}^{\prime}(1)^{T}}{n} \\
\hat{F}(t / n)=\frac{\sum_{i=1}^{t} x_{i}}{n} \\
\widehat{F}^{\prime}(t / n)=\frac{\hat{F}(t / n)-\hat{F}(t / n-m / n)}{m / n}
\end{gathered}
$$

and $m=n^{0.05}$, as suggested by Bierens (2000).

In Table 2 we present the results of the nonlinear co-trending analysis by Bierens (2000)

\section{Table 2: Test for the number of co-trending vectors}

\begin{tabular}{|r|r|r|r|r|r|r|r|r|r|}
\hline $\mathrm{r}$ & Brazil & Denmark(1) & Denmark(2) & $\begin{array}{l}\text { Hong } \\
\text { Kong }\end{array}$ & Iceland & Indonesia & $\begin{array}{r}\text { Rep. } \\
\text { Korea }\end{array}$ & Singapore & USA \\
\hline 1 & 0.11 & 0.08 & 0.11 & 0.25 & 0.11 & 0.23 & 0.17 & 0.22 & 0.23 \\
\hline 2 & $1.14 * *$ & $1.14 *$ & $0.60^{*}$ & $1.39 * *$ & $1.12^{* *}$ & $1.13 * *$ & $1.54 * *$ & $0.94 * *$ & $1.59 * *$ \\
\hline
\end{tabular}

Note: The null of $r$ cotrending vectors is tested against the alternative of $r$ - 1 . The symbol ** represent rejection of the null at the $5 \%$ and $*$ at the $10 \%$. The $5 \%$ critical value for $r=1$ is 0.46 and for $r=2$ is $0.67(5 \%)$ and $0.53(10 \%)$.

From Table 2 we can highlight that it is clear that in all cases there is evidence that the series share a common trend, as $r=1$ cannot be rejected whereas $r=2$ is rejected in most cases at the $5 \%$ level, hence they share a co-movement. As above mentioned, this is indicative that the variables share commonalities, probably similar fundamentals, within each of the countries.

In Figure 1 we plot the nonlinear co-trending relations along with the co-trending vectors. As we can see, in all cases except in Denmark(2), Hong Kong and Indonesia the co-trending parameter is great than 1, indicating that residential real estate prices tend to be more volatile that commercial housing prices. Interestingly, the coefficient is around 2, implying that movements of 1 unit in the price of commercial real estate transmit around double to the residential housing prices. 


\section{Figure 1: Plots of the nonlinear cotrending relations}



Solid line: DEN1_RES

Dotted line: 2.1559xDEN1 COM



Note: XX_RES refers to the plot for residential properties, and XX_COM refers to the plot for commercial properties. 
Figure 1 (continued): Plots of the nonlinear cotrending relations

Solid line: DEN2_RES

Dotted line: $0.8403 \times D E N 2 \_C O M$

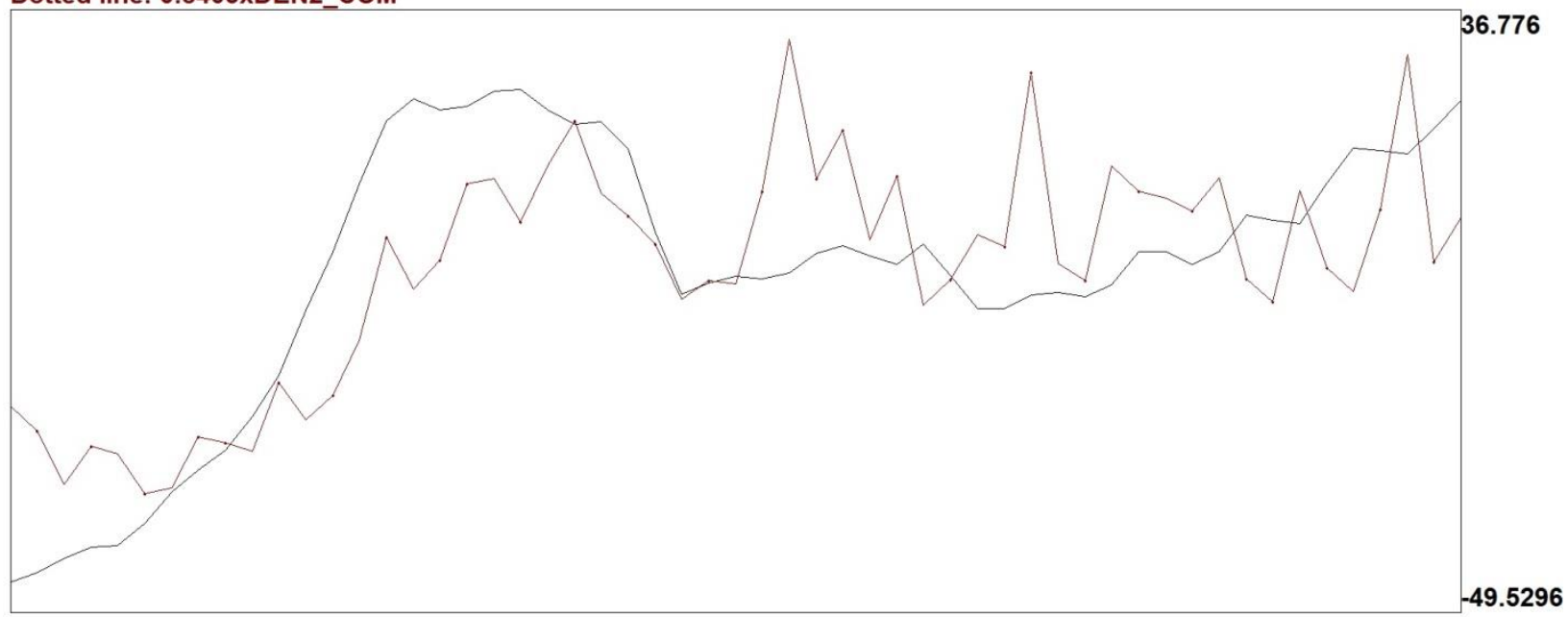

Solid line: HK RES

Dotted line: $0.6723 x H K \_c O M$

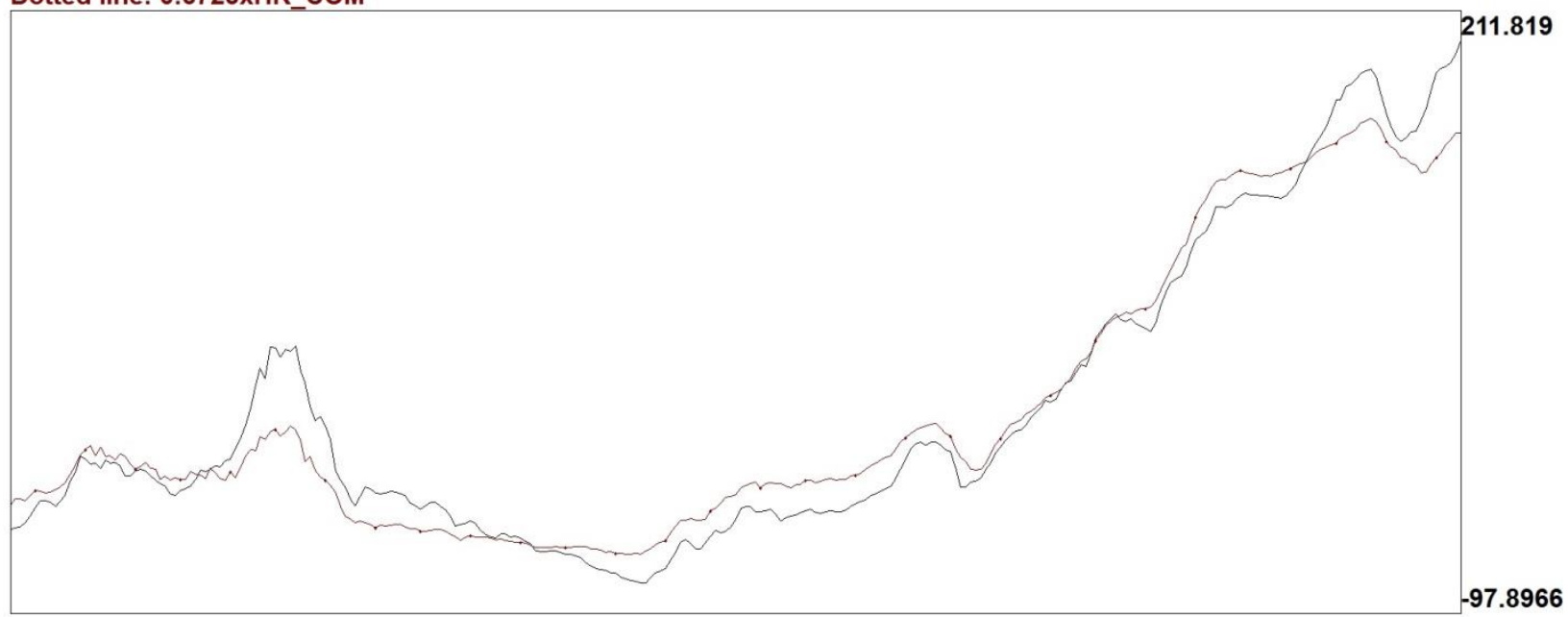

Note: XX_RES refers to the plot for residential properties, and XX_COM refers to the plot for commercial properties. 


\section{Figure 1 (continued): Plots of the nonlinear cotrending relations}

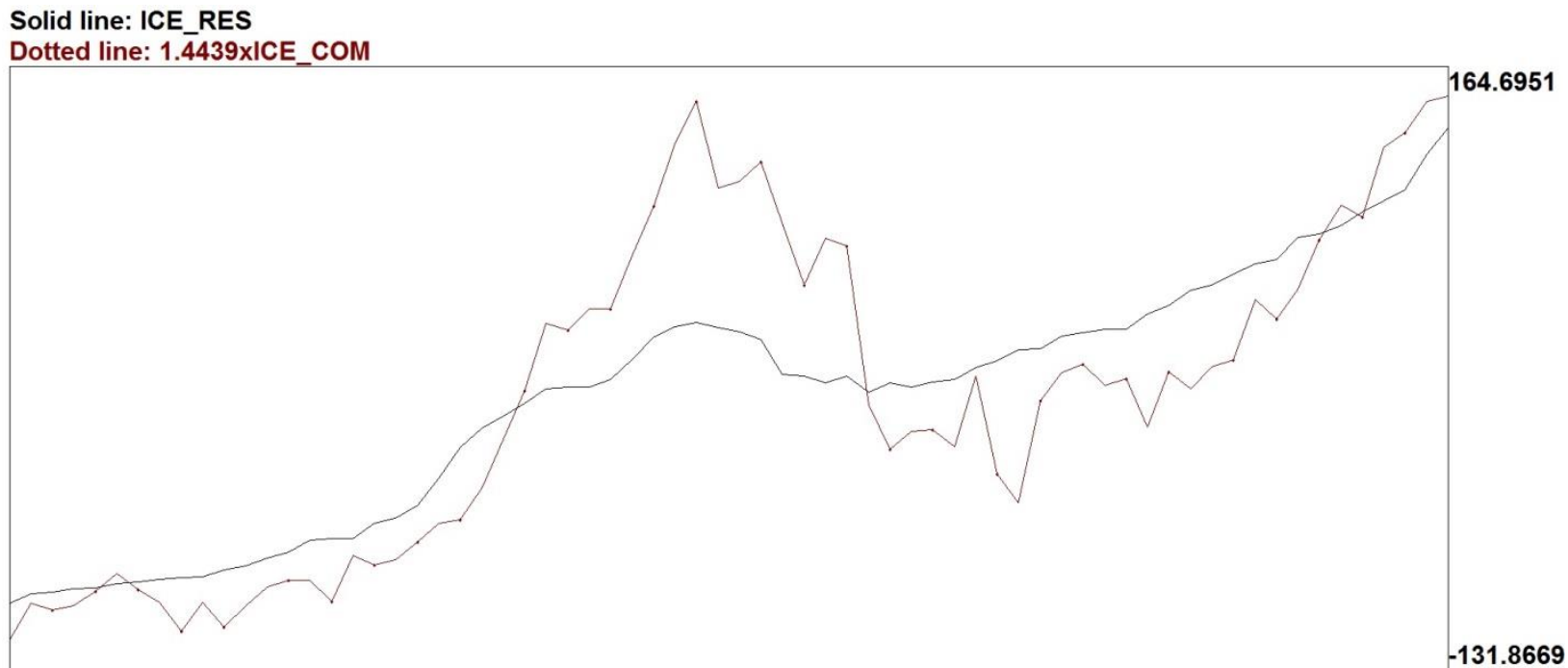

\section{Solid line: IND_RES}

Dotted line: $0.3781 x$ IND_coM

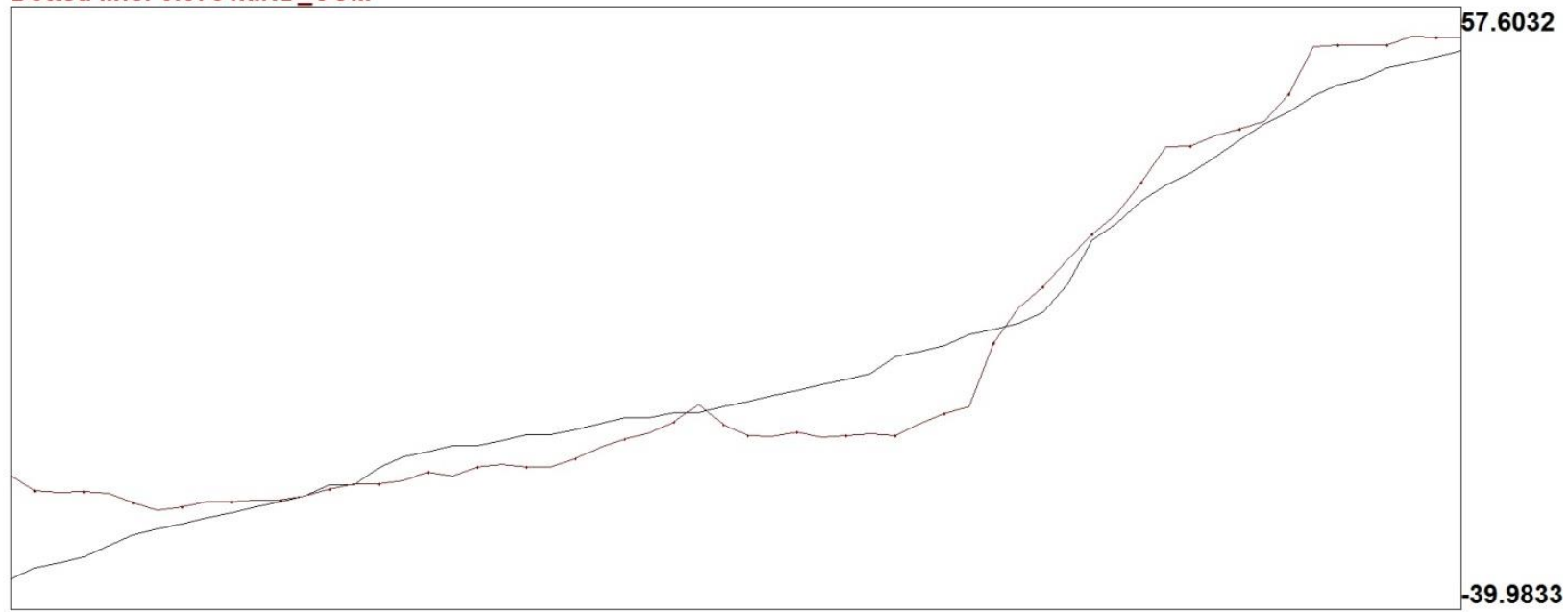

Note: XX_RES refers to the plot for residential properties, and XX_COM refers to the plot for commercial properties. 
Figure 1 (continued): Plots of the nonlinear cotrending relations

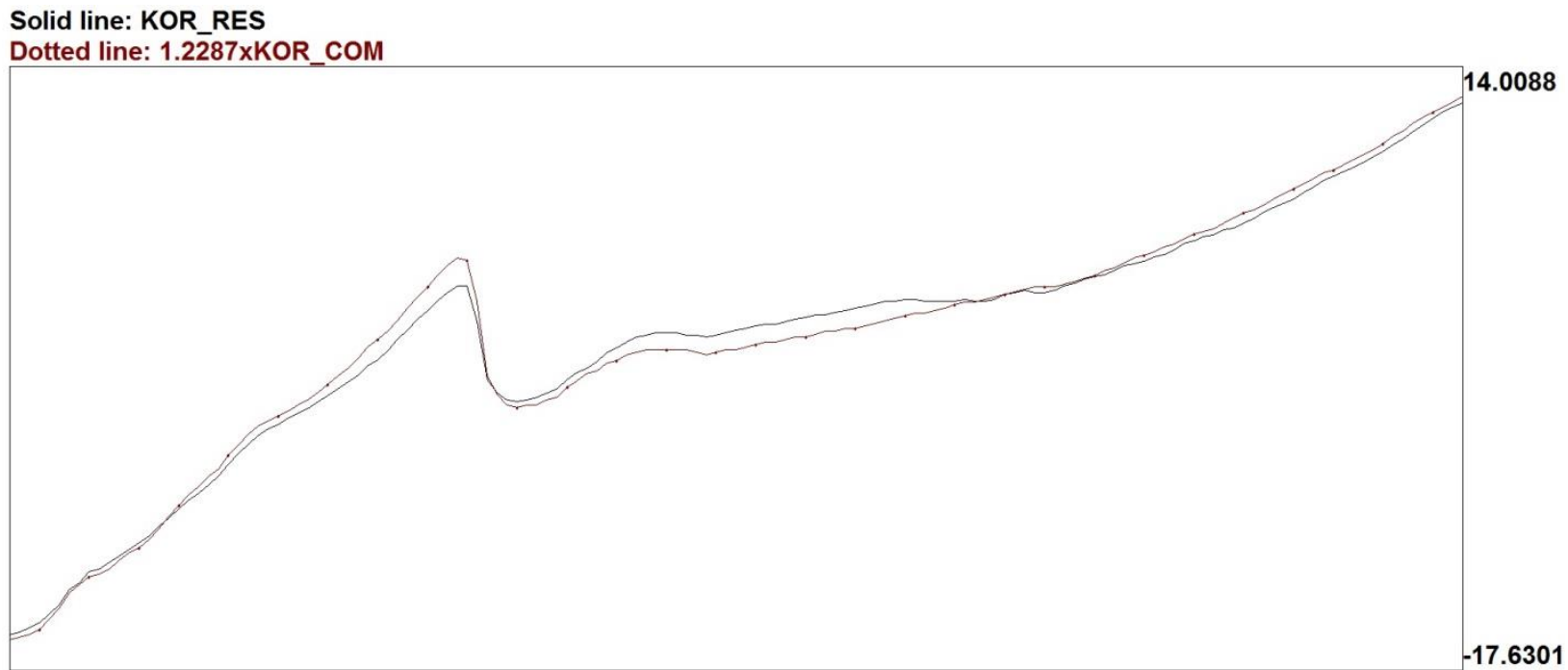

Solid line: SIN_RES

Dotted line: $2.5083 \times$ SIN_COM

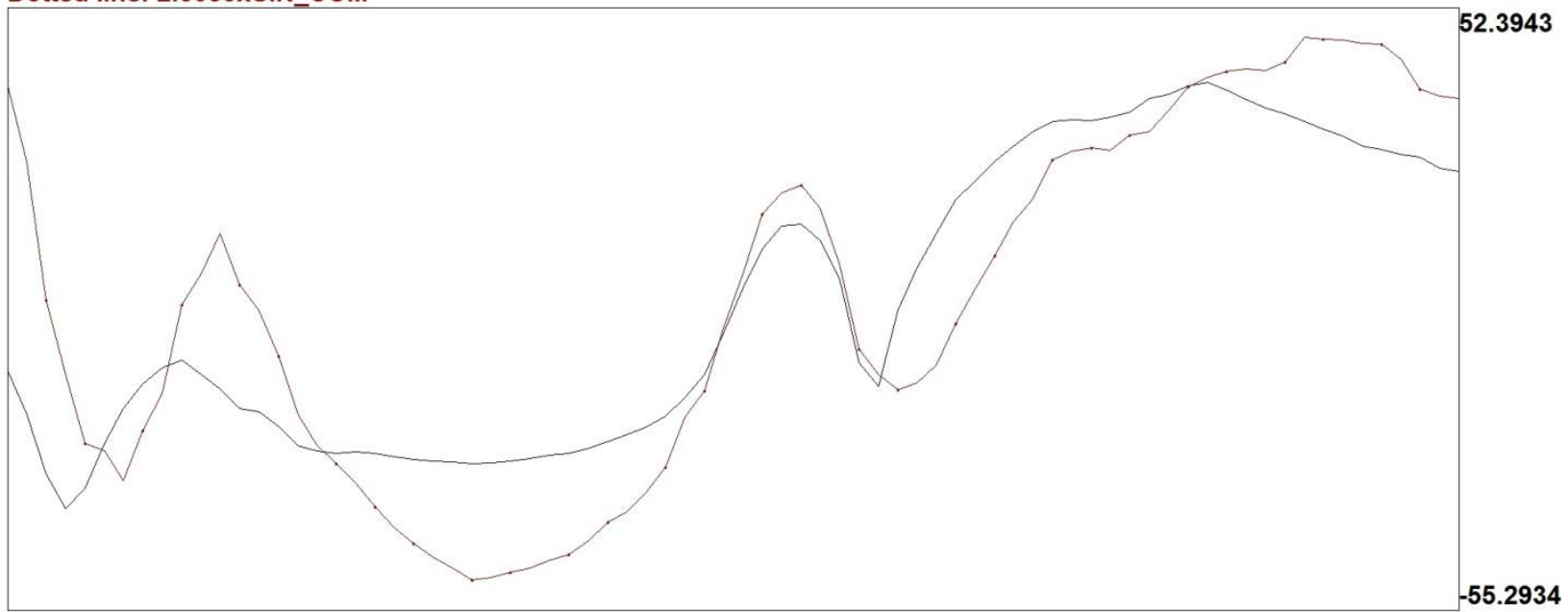

Note: XX_RES refers to the plot for residential properties, and XX_COM refers to the plot for commercial properties. 


\section{Figure 1 (continued): Plots of the nonlinear cotrending relations}

Solid line: USA_RES

Dotted line: 1.8915xUSA_COM

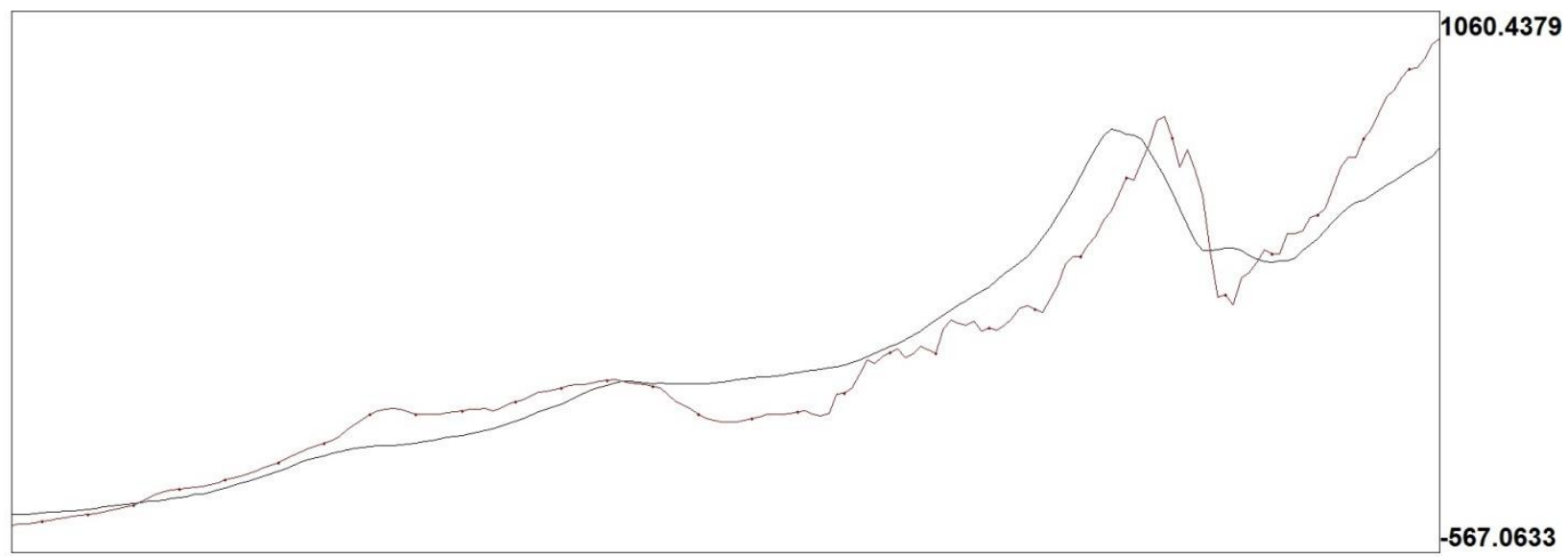

Note: XX_RES refers to the plot for residential properties, and XX_COM refers to the plot for commercial properties. 


\section{Conclusion}

Aiming to contribute to the literature on housing markets, in this paper we have analysed whether the prices of commercial and residential dwellings share a co-movement. We have used a recently published database by the BIS. Our results highlight the fact that residential and commercial property prices share a common trend in the countries analysed. These results imply that policies aimed at affecting the prices in one market also have an impact on the other. 


\section{References}

Bianchi, D., M. Guidolin and F. Racazzolo (2015): "Dissecting the 2007-2009 real estate market bust: Systematic pricing correction or just a housing fad? IGIER-Universta Bocconi, Working Paper no. 567.

Bierens, H. J. (2000): "Nonparametric Nonlinear Cotrending Analysis, with an Application to Interest and Inflation in the United States", Journal of Business and Economic Statistics, vol. 18, pp. 323-337.

Cuestas, J.C. (2017): "House prices and capital inflows in Spain during the boom: evidence from a cointegrated VAR and a Structural Bayesian VAR", Journal of Housing Economics, vol. 37, pp. 22-28.

Cuestas, J.C. and M. Kukk (2019): "The Spanish Housing Market: Is It Fundamentally Broken?" Applied Economics Letters, forthcoming.

Hlavacek, M., O. Novotny and M. Rusnak (2014): CNB Financial Stability Report 2013/2014, chapter Thematic Article 4, pages 148-155.

Gupta, R. and S. Das (2008): "Spatial Bayesian methods of forecasting house prices in six metropolitan areas of South Africa", South African Journal of Economics, vol. 76, pp. 298-313.

Gupta, R., C. Andre and L. Gil-Alana (2015): "Comovement in Euro area housing prices: A fractional cointegration approach", Urban Studies, vol. 52, pp. 3123-3143.

Gyourko, J. (2009): "Understanding Commercial Real Estate: How Different from Housing Is It?", Journal of Portfolio Management, vol. 35, pp. 23-37.

Roback, J. (1982): "Wages, rents, and the quality of life", Journal of Political Economy, vol. 90, pp. 1257-78. 
Rosen, S. (1979): "Wage-based indexes of urban quality of life". In Current Issues in Urban Economics, edited by Peter Mieszkowski and Mahlon Straszheim. Baltimore: Johns Hopkins University Press. 